\title{
Working
}

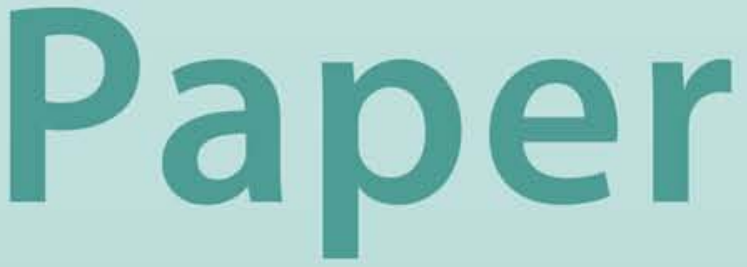




\section{Recent Advances in Credit Risk Modeling}

Christian Capuano, Jorge Chan-Lau, Giancarlo Gasha, Carlos Medeiros, Andre Santos, and Marcos Souto 


\title{
IMF Working Paper
}

Monetary and Capital Markets Department

Recent Advances in Credit Risk Modeling

Prepared by: Christian Capuano, Jorge Chan-Lau, Giancarlo Gasha, Carlos Medeiros, Andre Santos, and Marcos Souto ${ }^{1}$

August 2009

\begin{abstract}
This Working Paper should not be reported as representing the views of the IMF. The views expressed in this Working Paper are those of the author(s) and do not necessarily represent those of the IMF or IMF policy. Working Papers describe research in progress by the author(s) and are published to elicit comments and to further debate.

As is well known, most models of credit risk have failed to measure the credit risks in the context of the global financial crisis. In this context, financial industry representatives, regulators and academics worldwide have given new impetus to efforts to improve credit risk modeling for countries, corporations, financial institutions, and financial instruments. The paper summarizes some of the recent advances in this regard. It considers modifications of structural models, including of the classical Merton model, and efforts to reconcile the structural and the reduced-form models. It also discusses the reassessment of the default correlations using copulas, the pricing of credit index options, and the determination of the prices of distressed debt and estimation of recovery values.
\end{abstract}

JEL Classification Number: $\quad$ G000

Keyword: credit risk

Authors’ E-Mail Addresses: ccapuano@imf.org; jchanlau@imf.org; ggasha@imf.org;

cmedeiros@imf.org; asantos2@imf.org; and msouto@imf.org

\footnotetext{
${ }^{1}$ The authors would like to thank Christopher Morris and other colleagues in the Fund for many useful discussions on credit risk modeling during the preparation of this working paper over the course of the last year.
} 


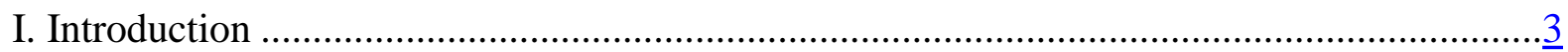

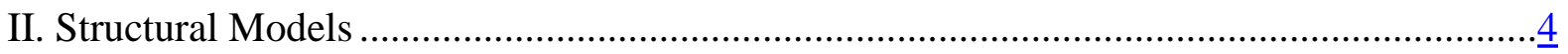

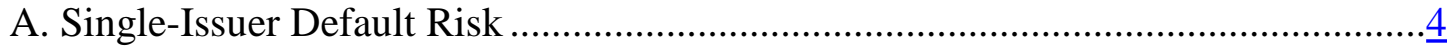

B. Distance-to-Default: Variations on a Theme ........................................................ $\underline{6}$

C. Portfolio Credit Risk Models ........................................................................... $\frac{7}{2}$

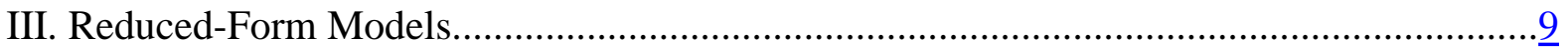

A. Structural and Reduced-Form Models: Reconciliation Attempts ............................ $\underline{9}$

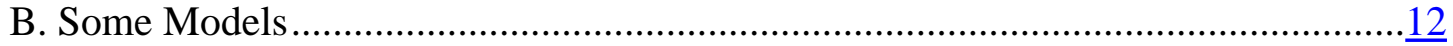

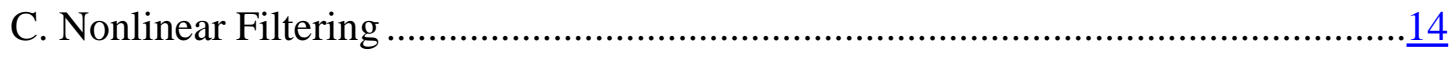

IV. Other Innovations in the Modeling of Credit Risk .................................................. 17

A. Default Correlation Using Copulas and Other Recent Approaches....................... $\frac{17}{20}$

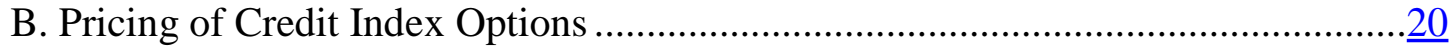

C. Distressed Debt Prices and Recovery Rate Estimation ..........................................21

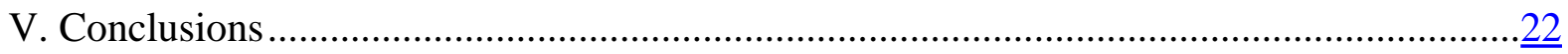

Figure

1. Dah-Sing Bank: Distance-to-Default ...........................................................................

Boxes

1. Compensators and Pricing Trends: Some Definitions_Elizalde (2006) ..........................11

2. The Modeling Strategy of Frey, Schmidt, Gabih (2007) ................................................

Appendix

Filtration and the Pricing of Credit Index Options ..........................................................24

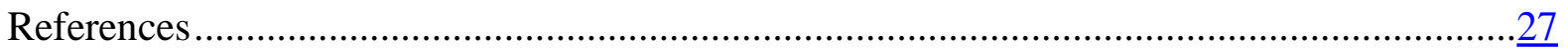




\section{INTRODUCTION}

As is well known, most models of credit risk have failed to measure the credit risks in the context of the global financial crisis. The failure of these models has made it difficult, if not impossible in some cases, for investors to manage the credit risk associated with countries, corporations, financial institutions, and even some financial instruments. This failure reflects partly the fact that the critical assumptions or elements that underlie these models have lacked the needed flexibility to take into account the recent changes in economic and financial circumstances or occurrence of extreme events. ${ }^{2}$ Such a failure also demonstrates that the correlations of the factors that drive credit risk in these models have broken down in the context of the crisis. Not surprisingly, most models of credit risk have then provided little guidance for the management of credit risk.

In this context, financial industry representatives, regulators and academics worldwide, among others, have given new impetus to efforts to improve the modeling of credit risk. This reflects the critical need to both measure and manage credit risk in the context of what has become the worst global financial crisis in recent memory. To this end, these interested observers have begun to change or innovate key assumptions and elements of the modeling of credit risk. They have taken steps to look at changes or innovations to both structural models, which consider that a default occurs whenever the value of the assets underlying the liabilities falls below some threshold, and reduced-form models, which depend on a random default time whose distribution depends on economic variables. They have stressed the need to include jump terms based on Poisson distributions in the modeling of credit risk, while incorporating a robust assumption of filtration, or the observed developments of the factors that drive credit risk. Emphasis also has been given to the benefits of including variable recovery rates in the modeling of credit risks. In addition, they have highlighted the need to develop simple but robust models to assess the credit risk of structured financial instruments.

The paper summarizes some of the recent advances in the modeling of credit risk, including by Fund staff. This paper considers the modifications of the structural models, and efforts to reconcile the structural and the reduced-form models. It also mulls over the reassessment of the default correlations using copulas, the pricing of credit index options and the importance of filtration in this regard, the use of nonlinear filtering, and the determination of the prices of distressed debt and estimation of recovery values. Even though the paper attempts to simplify the exposition of these innovations, it falls short in many respects not least because the innovations make use of ever more complex techniques and methodologies of a number of disciplines, including mathematical statistics and financial economics.

\footnotetext{
${ }^{2}$ Another important factor that contributed to the global financial crisis was the misuse of credit risk models in investment banks and credit rating agencies, a problem associated with governance issues and conflicts of interest between revenue producing units, such as underwriters and proprietary trading desks and risk management units.
} 
The paper is divided as follows. Section II describes the recent modifications of structural models of default risk, including both of single issues and multiple issuers. Section III explains the recent attempts to reconcile the structural and reduced-form models. Section IV summarizes other innovations in the modeling of credit risk. This section includes a summary of the recent work on default correlations using Copulas, the pricing of credit index options, and the latest work on distressed debt prices and recovery rate estimation. Section V provides a conclusion.

\section{STRUCTURAL MODELS}

\section{A. Single-Issuer Default Risk}

\section{Default-at-maturity and first-passage time models}

As is well known, two main approaches are in use for modeling the default risk of a single issuer: the intensity-based or reduced-form and structural approaches. The reduced-form approach assumes that the timing of default depends on an exogenous stochastic process, and the default event is not linked to any observable characteristic of the firm. In contrast, the structural approach, which traces its roots to Black and Scholes (1973) and Merton (1974), starts with the observation that default occurs when a firm is unable to continue servicing its debt, say, because of economic reasons related to the business cycle. ${ }^{3}$ Under absolute priority rules, equity shareholders are residual claimants on the assets of the firm since bondholders are paid first in case of default. Equity shareholders, in effect, hold a call option on the assets of the firm, with a strike price equal to the debt owed to bondholders. Similarly, the value of the debt owed by the firm is equivalent to a default-free bond plus a short position on a put option on the assets of the firm.

Structural models rely on the conceptual insight that default occurs when the asset value of the firm is less than what the firm owes to its debtors. However, these models differ with respect to their assumptions regarding the timing of default. In the model of Merton (1974) as in other structural models, for a firm that issues a zero-coupon bond, ${ }^{4}$ default occurs at maturity since this is the only period in which creditors can verify the asset value of the firm. These are examples of default-at-maturity models. In other structural models, default occurs the the asset value of the firm, $V$, falls below the value of the liabilities of the firm, $L$, at some default time $\tau$. The problem of default, in mathematical language, is equivalent to a first passage time problem, also known as a first stopping or exit time problem. ${ }^{5}$ First passage time models include, among others, those of Kim, Ramaswamy, and Sundaresan (1993), Nielsen, Saá-Requejo, and Santa-Clara (1993), Longstaff and Schwartz (1995) and SaáRequejo and Santa Clara (1999).

\footnotetext{
${ }^{3}$ See Duffie and Singleton (2003), among others, for a textbook treatment of the structural and reduced-form approaches to credit risk.

${ }^{4}$ See Geske (1977) for an extension to coupon bonds.

${ }^{5}$ For a comprehensive discussion of stopping times, see Karatzas and Shreve (1991) or Protter (1992).
} 
More recently, Capuano (2008) has proposed a non-parametric structural model to estimate the probability of default. This model estimates the probability of default implied by equityoptions by calibrating the probability density function of the value of the assets using the market prices of option contracts. Such a model makes it possible to estimate the default barrier within the model, while capturing deviations from log-normality. The model has performed well in the context of the global financial crisis, providing early warning signals of distress for some key financial institutions. (IMF, 2009).

\section{Distance-to-default}

Structural models rely on the concept of distance-to-default. This concept is a standardized measure of the difference between the firms' asset and liability values, which, theoretacally, depends on the option-like features of the equity value of a firm. Such features are derived from an elementary accounting identity whereby the value of the firm, $V$ (or the value of its assets), is equal to the sum of the values of its debt, $D$, and equity, $E$. Because debt is senior to equity, shareholders are residual claimants on the firm: the firm's assets are first used to pay debt holders in case of default, and whatever is left is distributed to shareholders. Concisely, the value of equity can be written as

$$
E=\max (0, V-D)
$$

The payoff to equity holders is equivalent to a call option on the value of the firm with a strike price equal to the face value of debt. The strike price is also known as the default barrier. Given an option pricing formula, knowledge of any two of the following three variables - the value of the firm, the debt owed by the firm, and the market value of equityis sufficient for estimating the remaining unknown variable.

Tthe Black-Scholes-Merton option pricing formula for European call options is the basis for most practical applications. The strike price is set equal to the level of the firm's short-term liabilities and half its long-term liabilities. For the Merton (1974) model, the distance-todefault $T$ periods ahead, $D D_{T}$, is given by

$$
D D_{T}=\frac{\ln \frac{V}{D}+\left(\mu-\frac{1}{2} \sigma^{2}\right) T}{\sigma \sqrt{T}}
$$

where $\mu$ is the growth rate of the asset value of the firm and $\sigma$ is the asset volatility. Equation (II.2) simply states that the distance-to-default is the expected difference between the asset value of the firm relative to the default barrier, after correcting and normalizing for the volatility of assets.

The distance-to-default measure has become a useful measure to assess the credit risk of nonfinancial corporations. ${ }^{6}$ Empirical results by Moody’s KMV have shown that the distance-to-

\footnotetext{
${ }^{6}$ Crosbie and Bohn (2003), and Vassalou and Xing (2004).
} 
default predicts well corporate defaults. Furthermore, work by Gropp, Vesala and Vulpes (2002), and Chan-Lau, Jobert, and Kong (2004) shows that the distance-to-default predicts banks' downgrades in developed and emerging market countries. For instance, the figure below shows the evolution of the distance-to-default of Dah-Sing Bank, a Hong Kong SARbased bank. Clearly, the distance-to-default of the bank points towards a substantial credit quality deterioration in the second half of 1997, while showing a recovery to pre-crisis levels in mid-2001.

Figure 1. Dah-Sing Bank: Distance-to-Default

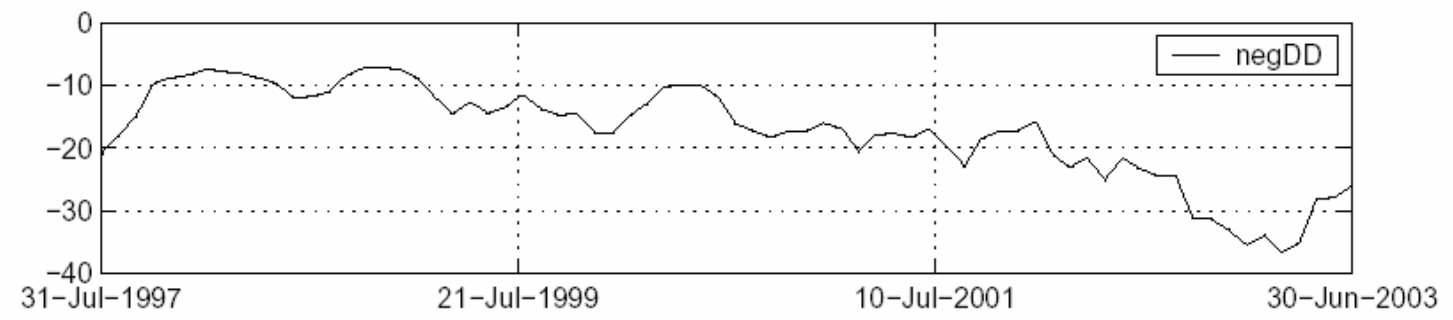

B. Distance-to-Default: Variations on a Theme

Different variations of the distance-to-default arise from the use of different option pricing formulas and/or different calibration procedures. The appropriateness of the assumptions underlying specific distance-to-default of a particular institution and the quality of the data used for calibration are critical in this regard. For instance, illiquid stock markets may yield little information about the profitability and, therefore, the default risk of a firm. As described below, it is possible to adapt the basic distance-to-default to particular situations.

\section{Currency mismatches in the balance sheet}

A currency mismatch exists when a borrower funds its operations in one currency, while the earnings derived from these operations accrue in another currency. In emerging market countries, and especially Latin America, currency mismatches in the corporate sector arise from balance sheets heavily tilted towards foreign-currency-denominated debt and localcurrency-denominated assets and/or earnings.

Modeling the impact of changes in the exchange rate into the standard distance-to-default based in Merton (1974) is a rather involved process that requires giving up the assumption that the default barrier is fixed and allowing it to change it stochastically. Nevertheless, borrowing on advanced option pricing theory, it is possible to derive tractable formulas for different assumptions regarding the behavior of the exchange rate. Furthermore, the distanceto-default can be estimated using simple maximum likelihood techniques as shown in ChanLau and Santos (2006).

\section{Prompt corrective action frameworks in the banking system}

Despite the empirical support for using the distance-to-default for assessing distress in financial institutions, the definition of default embedded in this measure may not capture the regulatory and supervisory complexities associated with bank interventions and closures. The distance-to-default may well understate the likelihood that a bank may be required to 
undertake corrective actions by regulators. The distance-to-default may, in effect, represent a "bridge too far" for regulatory purposes.

On a first pass, the problem may appear intractable. However, as shown by Chan-Lau and Sy (2006), the default barrier can be adapted in a relatively simple way to account for the trigger thresholds prescribed by prompt corrective action, which leads to a similar measure better defined as distance-to-regulatory capital. The choice of option pricing models and calibration methodologies to estimate this measure involves the same selection as the methodologies to approximate the distance-to-default.

\section{Sovereign risk}

The distance-to-default is now in use to measure credit risk of sovereign countries. ${ }^{7}$ The main caveat arises from the fact that the mapping of the concepts of corporate equity and asset value to a sovereign country is not straightforward. Also, there is an important implicit assumption that equity holders are subordinate to debt holders, which is not the case for a sovereign country. Ultimately, the proof of the usefulness of the use of distance-to-default depends on the empirical evidence: Is the distance-to-default a good empirical predictor of default? Is it highly correlated with other default indicators such as credit default swaps? So far, the answers have been positive.

\section{Portfolio Credit Risk Models}

Knowledge of the probability of default of individual firms opens the way to use portfolio credit risk models to assess the probability that a subset of the firms in a sample default during a pre-specified period of time. Put differently, if there is information about losses given default associated with securities issued by each single issuing firms, it is possible to estimate the loss distribution of a portfolio that holds these securities.

Assessing the probability of default among a subset of firms requires computing the distribution of the number of defaults. The multi-factor normal Gaussian copula, which was introduced by Vacisek (1987) and extended by Li (2000), is the workhorse structural model for such a computation,. ${ }^{8}$ In the Gaussian copula, the normalized asset value of firm $i, x_{i}$, depends on a single common factor, $M$, and an idiosyncratic shock, $Z_{i}$ :

$$
x_{i}=a_{i} M+\sqrt{1-a_{i}^{2}} Z_{i},
$$

where $x_{i}, M$, and $Z_{i}$ are standard normally distributed variables. The coefficient $a_{i}$, or factor loading, is restricted to values between 0 and 1 and measures the dependence of the asset

\footnotetext{
${ }^{7}$ See Gapen, Gray, Lim, and Xiao (2004).

${ }^{8}$ Section IV.A discusses the use of Gaussian copula in the context of the credit risk of structured securities.
} 
value on the common factor. For instance, a common factor could be the exchange rate or some economy-wide index.

Firm $i$ defaults when the asset value $x_{i}$ falls below a threshold value $\bar{x}_{i}$. The threshold value can be determined if the probability of default $q_{i}(t)$ for firm $i$ in period $t$ is known since $\bar{x}_{i}=\Phi^{-1}\left(q_{i}\right)$, where $\Phi$ is the cumulative standard normal distribution function. Once the threshold value is known, it follows that the conditional default probability is equal to:

$$
\operatorname{Prob}\left\{x_{i}<\bar{x}_{i} \mid M\right\}=q_{i}(t \mid M)=\Phi\left(\frac{\bar{x}_{i}-a_{i} M}{\sqrt{1-a_{i}^{2}}}\right) .
$$

The distribution of the number of defaults can be obtained using the recursive procedure proposed by Andersen, Sidenius, and Basu (2003). As in Gibson (2004), $p^{K}(l, t \mid M)$ is the probability of experiencing $l$ defaults during a time horizon $t$ conditional on the common factor $M$ for a set of $K$ firms. If the default distribution is known for $K$ firms, the default distribution if an additional firm is added to the set can be obtained from the following recursion:

$$
\begin{aligned}
& p^{K+1}(0, t \mid M)=p^{K}(0, t \mid M)\left(1-q_{K+1}(t \mid M)\right) \\
& p^{K+1}(l, t \mid M)=p^{K}(l, t \mid M)\left(1-q_{K+1}(t \mid M)\right)+p^{K}(l-1, t \mid M) q_{K+1}(t \mid M), l=1, \ldots, K \\
& p^{K+1}(K+1, t \mid M)=p^{K}(K, t \mid M) q_{K+1}(t \mid M)
\end{aligned}
$$

Recursion in these equations starts with the degenerate default distribution $p^{0}(0, t \mid M)=1$ for $K=0$ to determine the default distribution for a set of $N$ firms, $p^{N}(l, t \mid M), l=0, \ldots, N$. The unconditional default distribution $p(l, t)$ is obtained by integration:

$$
p(l, t)=\int_{-\infty}^{\infty} p^{N}(l, t \mid M) \phi(M) d M
$$

where $\phi$ is the standard normal distribution function.

Calibration of the one-factor Vacisek model requires first estimating the correlation of each firm's asset value with the common shock or factor. This correlation can be obtained using principal component analysis. Such a method assumes that a limited number of unobserved variables (or factors) explain the total variation of the larger set of variables. That is, the higher is the degree of co-movement across all individual firm default probability time series, the fewer is the number of principal components (factors) needed to explain a large portion of the variance of the original series. 
In the case where the original variables are identical (perfectly collinear), the first principal component would explain 100 percent of the variation in the original series. Alternatively, if the series are orthogonal to one another (i.e., uncorrelated), it would take as many principal components as there are series to explain all the variance in the original series. In that case, no advantage would be gained by looking at common factors, as none exist. Results obtained by Chan-Lau and Gravelle (2005) suggest that the first principal component accounts for around 70 to 80 percent of the variance.

A number of default-at-maturity and first passage time models accommodate different assumptions about the behavior of the exchange rate. The first model is a first passage time model that assumes that the exchange rate follows a diffusion process. The use of a diffusion process is indirectly validated by the empirical success of simple implementations of the Merton model in capturing default risk in both the corporate and banking sectors. ${ }^{9}$ The model is easy to calibrate since it yields simple closed form solutions. The second model is a default-at-maturity model, which assumes implicitly that the exchange rate follows a jumpdiffusion process. Empirical studies undertaken by Jorion (1988), Dumas, Jennergren, and Naslund (1995) and Bates (1996) find that jump-diffusion processes capture the behavior of exchange rates better than alternative models such as diffusion processes and stochastic volatility models. The third model is a first passage time model based on a double exponential jump-diffusion process (Kou, 2002). In contrast to jump-diffusion processes, the double exponential jump-diffusion process captures the stylized fact that the distribution of returns is asymmetric by specifying different probability distributions for positive and negative jumps. This model is well suited for analyzing situations under which the exchange rate is prone to move in only one direction, i.e. undervalued or overvalued exchange rate pegs.

\section{REDUCED-FORM MODELS}

\section{A. Structural and Reduced-Form Models: Reconciliation Attempts}

\section{Preliminaries}

As observed in the previous section, contrary to structural models, reduced-form models assume that the default event does not depend on the characteristics of the firm, which has prompted attempts by many authors to reconcile this difference. To this end, these authors have focused on the role that information structure plays in determining the predictability of the default event in structural and reduced-form models. Under certain conditions related to how information is revealed to the market participants, it is possible to show the equivalence between structural and reduced-form models. This section reviews work along these lines by, among others, Duffie and Lando (2001), Giesecke (2004, 2005), Giesecke and Goldberg

\footnotetext{
${ }^{9}$ See Crosbie and Bohn (2003) for corporates, and Gropp, Vessala, and Vulpes (2006) and Chan-Lau, Jobert, and Kong (2004) for banks in mature and emerging market countries, respectively.
} 
(2004), Çetin, Jarrow, Protter, and Yildirim (2004), and Guo, Jarrow, and Zen (2005a) to reconcile the differences between structural and reduced-form models.

The basic insight relates to what information is available to a modeler as explained by Jarrow and Protter (2004). They argue that the difference between the structural and reduced-form models reflects the information available to the modeler. While structural models assume that the modeler has the same information that the firm's manager has—complete knowledge of the processes of all the firm's assets and liabilities, which, in most situations, leads to a predictable default time-reduced-form models assume that the modeler has the same information set that the market has-incomplete knowledge of the firm's financial condition, which, in most cases, results in impossible to predict or "inaccessible" default time. As the information available to the modeler declines or shrinks, it becomes possible to transform a structural model in which default is a predictable stopping time into a reduced-form model in which default is an inaccessible stopping time.

A simple way to understand the argument offered by Jarrow and Protter (2004) is to focus on the simple structural model of Merton (1974). If the asset value is observed continuously, the default event is predictable in the sense that it is possible to observe if the asset value is moving towards the default barrier (or the face value of the firm's liabilities). However, if the asset value were to be observed only in relatively long, discrete intervals of time, it would not be possible to know whether the firm is close to default in between intervals. In the latter case, the default is unpredictable. ${ }^{10}$

In mathematical terms, the main difference between the structural and reduced-form models is one of the appropriate "filtration" process, or how information is conveyed to the market and how stopping times, e.g. default events, behave under different filtration. The structural models clearly make it possible to determine the default time. However, as the information available to the investor is "reduced," there is a need to consider a smaller filtration, which, depending upon the circumstances, could even make the default time completely inaccessible. As noted by Jarrow and Protter (2004), the difference between structural and reduced form models depends on whether the default time is part of a filtration that is observed by investors.

\section{Compensators and pricing measures}

The reconciliation between models requires the specification of structural models with incomplete information about the processes of assets, default threshold or both. The use of compensators to determine the default processes opens the way to determine the structural models' cumulative default rates or the so-called pricing trends (Box 1).

\footnotetext{
${ }^{10}$ Asset values are obtained from equity prices in most empirical implementation of structural models. Since equity prices are available at high frequencies, e.g. intra-day and intra-minute in some instances, it can be argued that equity-based structural models do not need to be reduced to an equivalent reduced-form model. However, this argument requires weak market efficiency, e.g. that current and past prices of equity and equityrelated securities contain all relevant information. If this is not the case, then the default event is not be predictable.
} 


\section{Box 1. Compensators and Pricing Trends: Some Definitions-Elizalde (2006)}

Definition 1. A stopping time $\tau$ is predictable if there exist a sequence of stopping times which announce $\tau$ such that:

$$
\begin{gathered}
\tau_{1} \leq \tau_{2} \leq \ldots<\tau \\
\lim _{n \rightarrow \infty} \tau_{n}=\tau
\end{gathered}
$$

And $\tau$ is considered a totally inaccessible stopping time if there does not exist any predictable stopping time which can give information about $\tau$, that is: $\operatorname{Pr}[\tau=\tilde{\tau}<\infty]=0$ for any predictable stopping time $\tilde{\tau}$. The default indicator process $N_{t}$ generated by $\tau$ is given by: $N_{t}=1_{\{\tau \leq t\}}$.

Definition 2. A process $C_{t}$ is called the $\left(F_{t}\right)$-compensator of the process $N_{t}$ if and only if:

- $C_{t}$ is a $\left(F_{t}\right)$-predictable increasing process, with $C_{0}=0$.

- The process $N_{t}-C_{t}$, called the compensated process, follow a $\left(F_{t}\right)$-martingale.

Definition 3. A process $\Gamma_{t}$ is said to be a pricing trend associated with the $\left(F_{t}\right)$-compensator $C_{t}$ such that:

$$
C_{t}=\Gamma_{\min \{t, \tau\}}
$$

The conditional default probability of this pricing trend can be expressed as:

$$
P\left[\tau \leq T / F_{t}\right]=E\left[e^{\Gamma_{t}-\Gamma_{T}} / F_{t}\right]
$$

Moreover, if a defaultable security which pays $X$ units at time $T$ if default has not occurred before $T$ and zero otherwise is considered, the price of the security at time $t \leq T$ can be expressed as:

$$
E\left[X e^{\Gamma_{t}-\Gamma_{T}-\int_{t}^{T} r_{s} d_{s}} / F_{t}\right]
$$

where $r_{t}$ is the $\left(F_{t}\right)$-adapted interest rate process. The two previous expressions for the conditional default probability and the price of the defaultable securities are similar to those observed in reduced models

where, if $\lambda_{\mathrm{t}}$ is the intensity process, $\Gamma_{\mathrm{t}}$ would be the cumulative default process $\int_{0}^{t} \lambda_{s} d_{s}$. The pricing trend $\Gamma_{\mathrm{t}}$ only admits an intensity representation when it is differentiable. In the cases where $\Gamma_{\mathrm{t}}$ is differentiable, there exists a process $\lambda_{t}$ such that: $\Gamma_{t}=\int_{0}^{t} \lambda_{s} d_{s}$, which represents the intensity of the counting process $N_{t}$, i.e., the intensity of arrival of the stopping time $\tau$. Therefore, the pricing trend is the cumulative default rate.

The pricing trend $\Gamma_{t}$ is characterized by a compensator process $C_{t}$ such that the difference between the default process $N_{t}$ and the compensator follows an $\left(F_{t}\right)$-martingale. If the filtration $\left(F_{t}\right)$ represents information that investors receive over time, different specifications of $\left(F_{t}\right)$ imply different compensator processes and, therefore, different pricing measures. The pricing trends are determined by the specification of a stopping time $\tau$, and an information framework $\left(F_{t}\right)$. This is the link between structural and reduced-form models. A structural model is a way of specifying a default time $\tau$ based on the economic time of the firm, or:

$$
\tau=\inf \left\{t \geq 0 / V_{t} \leq K_{t}\right\}
$$


where $V_{t}$ and $K_{t}$ are the firm's assets and default threshold, respectively. Equipped with a specification for the default time, each specification of the information $\left(F_{t}\right)$ available to investors with respect to the asset value and the default threshold processed yields a different pricing trend and, therefore, a different reduced-form model.

\section{B. Some Models ${ }^{11}$}

\section{Duffie and Lando (2001)}

Duffie and Lando (2001) consider a model in which the default time is fixed by the firm's managers so as to maximize the value of equity. Investors cannot observe the assets directly, and receive only periodic and imperfect accounting reports. Assuming a given Markov process, $A=\left(A_{t}\right)_{t \geq 0}$, where $A_{t}$ represents the firms value at time $t$, Duffie and Lando "obscure" the process A so that it can be observed only at discrete time intervals, and add independent noise. A discrete time process $Z_{t}=A_{t}+Y_{t}$ is obtained, where $Y_{t}$ is the added noise, and which is observed at times $t_{i}$ for $i=1, \ldots, \infty$. The authors derive the distribution of the firm's asset value conditional on investors' information, and, from this distribution, the intensity of default in terms of the conditional asset distribution and the default threshold. The particular specification of the default time $\tau$ and the filtration $\left(F_{t}\right)$ therefore make it possible to derive an intensity for the default time. The stopping time, $\tau$, is therefore inaccessible. The default time $\tau$ is transformed from a predictable stopping time into an inaccessible stopping time since it is unclear how the asset value evolves between the time of the observations of the asset value. Default could occur unexpectedly prior to the next observation. Under these circumstances, the structural model becomes a reduced-form model by obscuring and reducing the information.

\section{Giesecke (2005)}

Giesecke (2005) deals with the case of a structural model in which investors have complete information about the asset value but incomplete information about the default threshold. Although constant, the default threshold is not known by the investors, who are forced to work under a distribution function for the default threshold. The impossibility of observing the default threshold makes the default time an unpredictable event. In this case, investors calculate the pricing trend in terms of the distribution function for the threshold and the observable historical asset value. Giesecke also studies the cases of incomplete information for both the asset value and the default threshold. In contrast with the previous case in which investors have incomplete information about the default threshold but complete information about the asset value process, this case with imperfect information about the pricing trendcalculated in terms of the threshold distribution and the distribution of the minimum historical asset level the pricing trend, calculated in terms of the threshold distribution and the distribution for the minimum historical asset level-admits an intensity representation.

\footnotetext{
${ }^{11}$ For a comprehensive survey of some of these models, see Jarrow and Protter (2004).
} 


\section{Giesecke and Goldberg (2004)}

Giesecke and Goldberg (2004a) consider the case in which the default barrier is random and unobserved-modeled as an horizontal line of the form $y=L$, where $L$ itself is unknown and random. Since this random curve is independent of the underlying structural model, the default time $\tau$ is inaccessible. Given that the true level of liabilities is not disclosed to the public, investors use a priory distribution for the default threshold.

Giesecke (2004) takes the incomplete information assumption in structural model one step further to model the default correlation. He provides a structural model in which the firms' default probabilities are linked via a joint distribution to their default thresholds. Investors do not have perfect information about either such thresholds or their joint distribution. However, they form a prior distribution which is updated when one such thresholds is revealed, which only happens when one of the firms defaults. In Giesecke (2004), investors have incomplete information about the firms' default thresholds but complete information about their asset processes. Giesecke and Goldberg (2004b) extend this framework to one in which investors do not have information about either the firms' asset values or their default thresholds. In this case, default correlation is introduced through correlated asset processes, and, again, investors receive information about the firms' asset and default barrier only when they default. Such information is used to update their priors about the distribution of the remaining firms' asset values.

\section{Çetin, Jarrow, Protter, and Yildirim (2004)}

Çetin, Jarrow, Protter, and Yildirim (2004) depart from a structural model—as in Duffie and Lando - where the modeler's filtration, $\left(F_{t}\right)$, is a strict subfiltration of that variable to the firm's managers - investors receive only a reduced version of the information that firm's managers have. The authors claim that the default time is a predictable event for firm's managers, since they have enough information about the firm's fundamentals. But investors do not have access to such information. Instead, investors observe a reduced version of this information. In the model, the firm's cash flow $(L)$ is the variable that triggers default, after reaching some minimum levels during a given period of time. Firm's managers can see $L$ levels, but investors only receive information about the sign of the $L$, making the default time an unpredictable event from their perspective. In this setting, investors derive the default intensity as seen by the market. The relevant barrier is now $L_{t}=0$, for all $t \geq 0$, the cash flows. Investors only observe whether the cash flow is positive, zero or negative, and assume that the default time is the first time that the cash flows fall below zero, or when the cash flow both remains below zero for a certain period of time, and then doubles in absolute magnitude. The default time is also inaccessible in this case. ${ }^{12}$

\footnotetext{
${ }^{12}$ Guo, Jarrow and Zeng (2005) argue that the way in which the previous papers introduce incomplete information about the variables generating default are illustrative but too simple to be applied in practice. Their paper represents a generalization to formalize the theory linking structural and reduced form models.
} 


\section{Jarrow, Turnbull, and others}

A class of reduced-form models that separates bankruptcy and the firm's underlying assets has attracted a lot of attention. These models rely on an approach suggested by Jarrow and Turnbull $(1995,1992)$ to price derivatives. The basic idea of this approach is to assume the presence of two exogenous stochastic term-structures - one risk-free and the other one that would be a credit spread over the first one-and bankruptcy that is an exogenous process, independent of the firm's underlying assets. The combined term-structure is then used to price instruments under the absence of arbitrage opportunities and using martingale technology (Harrison and Kreps (1979) and Harrison and Pliska (1981)). This approach does not require estimates for the parameters of the firm's unobservable asset value, a common problem in the structural models, or a payoff priority structure of the firm's liabilities.

By way of extension of this approach, Jarrow, Lando and Turnbull (1997) specify the bankruptcy process as a discrete Markov chain, whose parameters are easily estimated using observable data. Duffie and Singleton (1999) parameterize the losses at default as a reduction of the market value of defaultable securities observed at default, and show that these securities can be priced using a default-adjusted, risk-free rate process. They show that the price of the securities using their framework accounts for both the probability and timing of default, as well as the effect of losses on default. Guo, Jarrow and Zeng (2005b) model the recovery rate process within a reduced-form model using the firm's balance sheet structure. Wong and Wong (2007) develop a regime-switching model over the entire yield curve to examine the changes in default probabilities across different credit ratings.

\section{Nonlinear Filtering}

Nonlinear filtering problems usually arise in a "natural way" in structural models of credit risk with incomplete information about the value of assets or liabilities as in Duffie and Lando (2001), Jarrow and Protter (2004), and Frey and Runggaldier (2007).

Frey and Runggaldier (2007) study the pricing of credit derivatives in the context of incomplete information. They assume that the state variable process is not directly observable, and investors have information only on the default history of the portfolio and noisy price observations of traded credit derivatives. They address the filtering problems using a Markovian model where the unobservable factor or state variable process $X$ may jump at default times. In this context, they derive a finite-dimensional filter for the case where $X$ follows a finite-state Markov chain.

Frey and Runggaldier propose two steps for modeling the pricing of derivatives with incomplete information. In the first step, they propose a model where the state process $X$ driving the default intensities is observable. This so-called full-information model makes use of Markov-process techniques. In the second step, they study the pricing of derivatives in a more realistic setup of incomplete-information, which is built by projecting the default intensities and price dynamics from the full-information model onto the information $\left(F_{t}{ }^{I}\right)$ available to investors. $\left(F_{t}^{I}\right)$ contains the default history $\left(H_{t}\right)$ of the portfolio under consideration and noisy price observations for traded credit derivatives, which are modeled using $Z$ observations of nonlinear functions of the state process $X$ in additive Gaussian noise. 
The second step leads to a nonlinear filtering problem. This reflects the fact that the estimation of the conditional distribution of $X_{t}$ depends on the information available to the investors, or $F_{t}^{I}$. Frey and Runggaldier consider that the state process $X$ and the default indicator process $Y$ have a common jump, which makes the filtering problem particularly complex: $X$ and $Y$ cannot be made independent by a change-of-measure or viewing the same process under a different set of likelihoods. ${ }^{13}$ They then derive the filter by exploiting the recursive structure of the default history $\left(H_{t}\right)$. In so doing, they employ recursive solutions using a finite-dimensional filter in the case when $X$ is a finite-state, continuous-time Markov chain. The filter for such a Markov chain can be a useful tool for evaluating the filter for general state variable processes of jump-diffusion type.

Frey and Runggaldier (2008) use nonlinear filters in both interest rate and credit risk models with incomplete information. In particular, they employ the filters to price credit derivatives. Box 2 provides a general description of the use of nonlinear filters for modeling credit risk.

\footnotetext{
${ }^{13}$ Analysis of common jumps may be found also in Ceci and Gerardi (2001).
} 


\section{Box 2. The Modeling Strategy of Frey, Schmidt, Gabih (2007)}

Frey, Schmidt, Gabih (2007) present a modeling strategy for the pricing and hedging of credit derivatives based on three layers of information. They consider defaultable securities issued by $m$ firms, while noting that the random time $\tau_{i}$ denotes the default time of firm $I ; Y_{t, i}=1_{\{\tau i \leq t\}}$ is the corresponding default indicator; and $Y_{t}=\left(Y_{t, 1}, \ldots, Y_{t, m}\right)$ gives the current state of the portfolio. They also assume that the default intensities (the intensities of the multivariate point process $Y$ ) depend on some factor process $X$. They also consider three layers of information: full information; information of informed market participants (market information); and information of secondary-market-investors (investor-information).

Full Information. The authors assume a filtered probability space $(\Omega, \Pi, F, Q)$ with $Q$ being the risk neutral measure, and $\mathrm{F}$ the full-information filtration. They also assume that $\tau_{i}$ is conditionally independent doubly stochastic random times with $(Q, F)$-default intensity $\lambda_{t, i}=\lambda_{i}\left(X_{t}\right) ; X$ follows a finitestate Markov chain; and the risk-free rate equal to zero. They define the full-information value of $a \prod_{T}^{Y}$ measurable claim $P$ (such as a typical credit derivative) by $E^{Q}\left(P / \Pi_{t}\right)$-and denote the natural filtration of process $Y$ as $F^{Y}$. By the Markov property of $(X, Y)$, the full-information value is given by $p_{t}\left(X_{t}\right)$ for some $\Pi_{t}^{Y}$-measurable function $p_{t}$.

Market Information. The authors assume that the prices of traded credit derivatives are determined by informed market participants. These participants have access to so-called market information, given by the filtration $F^{M}:=F^{Y} V F^{Z}$. The stochastic process $Z$ represents noisy observations of $X$ and can be viewed as an abstract form of "insider information." $Z$ is given by $Z_{t}=\int_{0}^{t} a\left(X_{s}\right) d s+d B_{t}$, where $B$ is a standard

F-Brownian motion independent of $X$ and $Y$. The market price of a traded security with payoff $P$ is defined as:

$$
\hat{p}_{t}:=E^{Q}\left(P / \prod_{t}^{M}\right)=E^{Q}\left(p_{t}\left(X_{t}\right) / \prod_{t}^{M}\right)
$$

Since $Y_{t}$ is known, to compute the market price $\hat{p}_{t}$ it is necessary to determine the conditional distribution of $X_{t}$ given $\prod_{t}^{M}$, given the probability vector $\pi_{\mathrm{t}}=\left(\pi_{\mathrm{t}}{ }^{1}, \ldots, \pi_{\mathrm{t}}^{\mathrm{k}}\right)$ with

$$
\pi_{t}^{k}=Q\left(X_{t} k / \Pi_{t}^{M}\right), 1 \leq \mathrm{k} \leq \mathrm{K}
$$

which is a nonlinear filtering problem. The authors solved the problem using martingale representation results, and the innovation approach to nonlinear filtering.

Investor Information. Since the process $Z_{t}$ is not directly related to observable economic quantities, the pricing and hedging of credit derivatives need to be analyzed from the view point of secondary market participants with information set $F^{I} \subset F^{M}$. It is assumed that $F^{I}$ contains the default history, $F^{Y}$, and the noisy price observations of traded credit derivatives. The authors show that, under this setup, the computation of prices and risk-minimizing hedging strategies lead to a second filtering problem in which the conditional distribution of the probability vector $\pi_{t}$ needs to be determined given investor information $\Pi_{t}^{I}$.

In this set up: (i) prices are weighted averages of full-information values, $\hat{p}_{t}$, and, therefore,

computations are done mostly in the context of a full-information model, which are relatively simple to handle; (ii) the fact that prices of traded securities are given by the projection of their full-information value on the market filtration $F^{M}$ leads to rich credit spread dynamics: spread risk (as credit spreads fluctuated in response to fluctuations in $Z$ ), and default contagion (as defaults of firms in the portfolio lead to an update of the conditional distribution of $X$ given $F_{t}^{M}$ and, therefore, a jump in the ( $Q, F^{M}$ )default intensities) are allowed; and (iii) the set up has a natural factor structure with factors given by the conditional probabilities $\pi_{t}^{k}, 1 \leq k \leq K$. 
IV. Other InNOVAtions IN THE MOdeling OF CREDit RISK

\section{A. Default Correlation Using Copulas and Other Recent Approaches ${ }^{14}$}

The nature of default correlation is related to the analysis of multiple defaults, which are typically observed in a portfolio of loans or a basket of securities, for example in collateralized debt obligations (CDOs). In this context, when modeling multiple random variables, it is necessary to analyze their multivariate distribution. This is where the dependence structure and correlation between the random variables become relevant. The same applies to multiple defaults. Since defaults are historically rare, they represent a tailevent of the distribution. As a consequence, default correlation relates to the modeling, in a multivariate framework, of the tail-dependence.

Following the traditional portfolio analysis, the multivariate normal distribution and the related Gaussian copula have been adopted for a generation of multiple defaults models. As described above, in its simplest (bi-variate) form, the Gaussian copula states that if we consider two standard normal random variables $x_{1}$ and $x_{2}$, with correlation $\rho_{12}$, the joint distribution of $x_{1}$ and $x_{2}$ will be bi-variate normal, and the degree of dependence between $x_{1}$ and $x_{2}$ will be entirely described by $\rho_{12}$. In this set-up, the $x_{i}$ 's would be percentile-topercentile transformation of the random variables describing the time to default of each firm or loan of interest.

One of the advantages of the copula framework, and the Gaussian copula in particular, is that the correlation can be modeled separately from the marginal density of each random variable. ${ }^{15}$ With more than two random variables, such as in a CDO, one common way to model the correlation structure has been through factor models, with the most common being the one-factor model. The one-factor model typically implies that the default of each variable $x_{i}$ is linearly affected by a common factor, $V$ and a specific idiosyncratic factor, $Z_{i}$, generally endowed with independent standard normal distributions. This structure ensures that the correlation between each pair of defaults $\left(x_{i}, x_{j}\right)$ remains linear.

The Gaussian copula, discussed in section II.C, generally relies on a top-down approach. In particular, given a choice of marginal probability distributions for the random variables, the researcher specifies a one factor (or multi-factor) Gaussian copula that summarizes the dependence among the variables. The advantages and, hence, the popularity of this approach relate to the intuitive specification, the relatively simple structure, and the existence of closed form solutions, which make this approach easily implementable.

\footnotetext{
${ }^{14}$ This section only touches on intensity default modeling, and does not cover default correlation based on the binomial and Poisson distributions, intensity correlation, and correlation in rating changes. Lando (2004) provides an extensive treatment of these topics.

15 This is a salient feature of the reduced form models.
} 
At a regulatory level, the Basel II framework developed by the Bank for International Settlements (BIS) is also based on assumption of top-down static correlations between different asset classes, BIS (2005). More recently, this assumption has been severely questioned given the rapid increase in correlations experienced by different classes in the face of the global financial crisis (Fitch Ratings, 2008, 2004).

The main drawbacks of the top-down approach relate to the problem of choosing the correct copula, and the optimal incorporation of new information into the framework, i.e. the framework is static.

Jarrow and Yu (2001) have made some efforts to overcome these drawbacks. In particular, they propose an asymmetric information framework in which companies are divided into primary, whose default is influenced only by macroeconomic variables, and secondary, whose default depends on the probability of default of other companies. This framework attempts to better incorporate new information concerning actual defaults.

Both the academic literature and financial industry representatives, however, have devoted considerable amount of effort to design bottom-up frameworks. Crouhy, Galai, and Mark (2000) present a detailed comparative analysis of the most popular credit risk models in the finance industry.

Fund staff have also developed credit risk models that take into account default correlation. Avesani, Liu, Mirestean and Salvati (2006) show how to extend the popular Credit Risk+ framework to account for correlated defaults. Specifically, they allow for a fixed degree of correlation in the risk factors that drive multiple defaults in a portfolio of loans. Avesani, Garcia-Pascual, and Li (2006) present a market-based default indicator based on a basket of CDS spreads. In this case, the correlation structure is specified by allowing the default probability of the CDS basket to be linked with the covariance of the stock returns of the underlying corporations. More recently, Huang, Zhou, and Zhu (2008) propose a framework to estimate default correlations from high-frequency return data, while IMF (2009) presents a new set of models aimed at estimating directly the joint distribution of defaults, thereby delivering a dependence structure (copula) in the portfolio that is not exogenously specified. In the face of the U.S. financial crisis, these models obtain interesting results from a financial stability purposes.

In this light, why has the literature recently moved away from the Gaussian copula in modeling default correlations? The answer is mostly an empirical one. While the Gaussian copula is tractable and intuitive, its empirical performance has been weak, particularly in the current crisis. It is possible to find many reasons that explain the failure of the Gaussian copula, but probably the most relevant one relates to the non-linearity of default dependence. ${ }^{16}$ While correlation is a linear concept - the covariance is a linear operator-

\footnotetext{
${ }^{16}$ The seemingly "failure” of the Gaussian copula, however, should not be overstated. Market practitioners mostly used the Gaussian copula as a pricing convention to quote prices for credit derivatives. The existence of a "correlation smile" is evidence that the market did not believe in the Guassian copula as the right pricing model. A more appropriate assertion perhaps is that the Gaussian copula was similar to the use of the Black-
} 
defaults tend to cluster during stress events, i.e. multiple defaults represent non-linear events. As a consequence, correlation is ill-suited to describe multiple defaults. More practically, the absence of any dynamics in the general Gaussian framework makes it also difficult to adopt it for hedging purposes.

The recent literature tries to address the empirical drawbacks of earlier models. An interesting approach to the modeling of multiple defaults, or an alternative to the choice of copula, is through network dependence as described by Eisenberger and Noe (2001). In this framework, firms are linked through cross-liabilities, which generate a matrix, i.e. a network, of inter-linkages. With sufficient detailed information, it is possible to design an optimal algorithm that generates contagion in the network and, therefore, correlation and multiple defaults, following the failure of one or more firms to honor its liabilities.

To account for default correlation in a basket of CDSs or an index such as the CDX, Couderc (2007) suggests first to use the entire information from the underlying default spreads and then to granularly model the discrete loss distribution of the index by compounding the (calibrated) correlations of the different tranches. It is also possible to introduce other types of structure along the line of the volatility smile in the Black-Scholes option pricing literature. Overall, it is still too early to determine the empirical success of these modifications, but the additional computational costs appear to represent a limiting factor.

Schönbucher (2008) proposes innovations to existing multivariate intensity models of credit risk that appear promising in capturing observed default correlations in time of distress. The main idea is to divide the information structure of the model into two parts: a pre timechange and a post time-change structure. In a pre time-change setting, defaults are conditionally independent; however, in a post time-change setting multiple defaults become conditionally dependent. In other words, an individual default is more likely when multiple defaults have already occurred. This observation suggests that perhaps what matters is not calendar time but "business" or "default" time, which is measured by the realization of defaults. The key to model "business" time is to accurately model the time-change stochastic process, while calibrating dependence to match any observed correlation. In this context, the problem becomes to separate the modeling of the time-change process, which intuitively account for the jump in the default dependence. Along these lines, Joshi and Stacey (2005) propose the use of Levy processes, in particular Variance Gamma processes, to account for time-change, which appears to capture the recent surge in default correlations.

Duffie, Horel and Saita (2008) present an empirical analysis of portfolio default losses on U.S. corporate debt during 1979-2004. Their results indicate that the probability of extreme portfolio losses can not be explained solely by observable risk factors. Even after accounting for both macro-and-micro observable risk factors, the authors find strong evidence for the presence of unobservable (latent) common factors. These results suggest that, in order to capture the observable time-variation in extreme default losses (tail events) in the U.S.

Scholes model for quoting equity options premia, or the Garman-Kohlhagen model for quoting the price of FXoptions. The existence of a "correlation smile” is akin to the volatility smile. 
corporate sector, it is of key importance to allow for latent factors to drive the portfolio loss distribution.

\section{B. Pricing of Credit Index Options}

Morini and Brigo (2007) offer a methodology to price credit swap options. The most common of these options is the credit index option, which is an option on the spread of a credit index that consists of a standardized portfolio of credit default swaps (CDS). The credit index option allows an investor to enter a forward credit index at a pre-specified spread, and to receive upon exercise of this option a front-end protection corresponding to index losses from option inception to option expiry. Conceptually, a payer credit index option at inception or time 0 , with a strike price $K$ and an exercise date $T a$, and written on an index with maturity $\mathrm{Tm}$ offers a buyer seeking protection the right (but not the obligation) to enter into an index at $\mathrm{Ta}$ with final payment at $\mathrm{Tm}$. The buyer pays a fixed $K$, which gives him the right to receive protection from losses in the period between $\mathrm{Ta}$ and $\mathrm{Tm}$. In addition, however, the buyer receives, upon exercise, the so-called front-end protection, which covers the losses from the option inception 0 to the exercise date $\mathrm{Ta}$. The front-end protection, therefore, provides the buyer with protection from losses in the period between 0 and $\mathrm{Ta}$. The credit index option includes the front-end protection as a way to attract more investors. Examples of this option are the iTraxx Europe that includes the CDS of equally-weighted European names, the iTraxx Crossover index that includes the most liquid subinvestment grade entities, and iTraxx HiVol that comprises a subset of the main index with the riskiest names.

According to Morini and Brigo, the pricing of the credit index options has undergone significant modifications over time. The initial market standard for pricing of credit index options centered on the use of a Black formula to price the option as a call on the spread, while adding the front-end protection. However, this market standard neglected the fact that it is not possible to separate the price of the option from the front-end protection since the latter is an integral part of the investor's decision to exercise the option. This led to a change in the market standard for the pricing of the credit index options that involved a redefinition of the underlying index spread.

Morini and Brigo, however, argue that the pricing of credit index options still suffers from shortcomings. They note that the index spread does not take into account the front-end protection in moments of stress in financial markets. They also indicate that the market practice to compute the index spread does not consider all states of the world. In addition, they note that it is not possible to justify theoretically the use of the Black formula in this context. They argue that, according to the fundamental theorem of asset pricing, a rigorous derivation of the Black formula for the pricing of a credit index option requires the definition of an appropriate numeraire for change of the pricing measure under which the underlying spread is a martingale. Since the index includes many defaultable names, the quantity that appears to be the natural choice of a numeraire is not strictly positive. To address this difficulty, it is possible to use a technique for single name products based on a numeraire that is not strictly positive. However, this measure would not be equivalent to the standard risk neutral, forward and swap measures used in mathematical finance. 
To address these shortcomings, the authors make a number of proposals. They offer a definition of an index spread that is generally valid, a description of the market payoff leading to a price defined in all states of the world, and a valid strictly positive quantity to define an equivalent pricing measure. They note that these proposals depend critically on a reconsideration of filtration, which makes it possible to compute a consistent, arbitrage-free definition of the underlying index spread (see Annex). ${ }^{17}$

Morini and Brigo note that the reconsideration of filtration makes it possible to price correctly credit index options. They stress that the use of such a tool opens the way for the replacement of the market option formula with the arbitrage-free option formula. As opposed to the market option formula that incorporates default correlation information directly, the arbitrage-free formula introduces an explicit dependence on default correlation information. In this vein, a severe event, or armageddon, is more likely to occur as default correlations increase. Empirical tests show that, under conditions of normalcy, the price of a standard index option using the market option formula, which includes both a price quotation and an implied volatility quotation, is not that different from the price using an arbitrage-free option formula. The differences amount to less than 1 basis point. However, in a situation of stress, such as in August 2007 that saw an increase in index spreads and correlations, the price of the index option using the market option formula differs in an important way from the price of the index option using the arbitrage-free option formula. By way of example, on that date, the price of a call index option using the market option formula differed by as much as 48 percent from the price of such an option using the arbitrage-free option formula because the perceived higher systemic risk had made the risk-neutral probability of an armageddon event not negligible.

\section{Distressed Debt Prices and Recovery Rate Estimation ${ }^{18}$}

Both structural and reduced-form credit risk models depend critically on assumptions about interest rates, default processes, and recovery rates. As noted by Guo, Jarrow and Lin (2008) and Jarrow (2008), structural models rely on the information available to the economic agents estimating the models. Default occurs the first time a company's asset value hits a liability barrier. If the company's asset value follows a continuous process, the value of the company's debt does not involve a jump at default. This model has no implications for risk debt prices after default. Reduced-form models use the information available to the market. Default occurs in the context of a first time jump in debt prices. Put differently, debt prices show a negative jump at default. Similar to the structural models, reduced-form models have little to say about risky debt prices after default.

While the literature on both interest rates and default rates is vast, it says little on recovery rates. ${ }^{19}$ The literature tends to rely on estimates of recovery rates by industry sources. As

\footnotetext{
${ }^{17}$ Karr (1993) and Kuo (2005) provide a formal definition of filtration.

${ }^{18}$ Based on Guo, Jarrow, and Lin (2008).

${ }^{19}$ See McNeil, Frey, and Embrechts (2005).
} 
these recovery rates are not always transparent, the literature tends to focus on the properties of these recovery rates. The literature also tends to use pre-default debt and CDS prices to estimate the recovery rates. However, it is not clear if the literature measures the recovery rates properly.

Guo, Jarrow and Lin attempt to address these shortcomings. To this end, they propose a direct estimate of recovery rates using the prices of distressed debt, and provide a model for distressed debt prices. They argue that it is necessary to estimate first the prices of the distressed debt, before determining a model for such prices. They begin by pointing out that recovery rate models tend to rely on three traditional cross-sectional models: recovery of face value (RFV); recovery of Treasury model (RT); and recovery of market value (RMV). The models are necessary inputs to price risky debt. The procedure to estimate the models requires (i) the identification of a defaulted company; (ii) the fixing of a date, $t$, to observe the debt prices; and (iii) the estimate of recovery rates. This procedure, in effect, involves estimating a recovery rate for a company, and a cross-sectional assessment across companies to obtain an overall estimate.

Guo, Jarrow and Lin extend the cross-sectional models of recovery rates to time-series models. In their view, the extension serves two purposes. First, this extension makes it possible to estimate the economic default rate, and to determine if this default rate differs from the recorded default rate. Second, such an extension opens the way to estimate the pricing of the distressed debt after the recorded default rate. The authors use a bound of 180 days before the recorded default rate, and information up to the point of the recorded default rate. In so doing, they find that the economic default rate differs significantly from the reported default rate. The industry estimate of the recovery rates based on 30 days after the recorded default appears to be mispecified.

Guo, Jarrow and Lin then provide a recovery rate model. The model assumes a standard continuous, time arbitrage free setting. The model recognizes the data limitations, and is consistent with the results of the time-series models. The authors employ the model to estimate the parameters of the recovery rate process and to price distressed debt. They find that this model explains well the recovery rates after the identification of the economic default date. In particular, they find that the average pricing error is less than one basis point in the sample database they use.

\section{Conclusions}

The modeling of credit risk has generated significant new interest because of the collapse of asset prices in the context of the global financial crisis. This reflects the fact that, with rare exceptions, models of credit risk have failed to take account the noticeable increase in the credit risk of countries, corporations, financial institutions, and financial instruments. This has made it difficult for economic agents to manage such risks, leading financial industry representatives, regulators and academics around the work to reassess the modeling of credit risk. This reassessment has taken into consideration the advances in the modeling credit risk before the crisis, while focusing on improvements in the structural models of credit risk, including the classical Merton's model, efforts to reconcile the structural and reduced-form 
models, and development of new models to measure the risks associated with complex financial instruments.

This paper summarizes some of the recent advances in the modeling of credit risk. In particular, this paper considers the main structural models, including default-at-maturity and first-passage models, while exploring some variations to these models, particularly with respect to currency mismatches, the balance sheet of economic agents, solvency risk, and the portfolio credit risk models. It also explores recent efforts to reconcile the structural and reduced-form models, and summarizes a number of reduced-form models. In addition, it considers other advances in the modeling of credit risk, including the use of default correlation using copulas, pricing of credit index options, and distressed debt price and recovery rate estimation. 


\section{Appendix: Filtration and the Pricing of Credit Index Options}

As noted by Morini and Brigo (2007), to understand the use of filtration to price credit index options, it is first necessary to understand the characteristics of these options. For a unit of forward credit index, each name has a notional of $1 / n$. The index quotations assume a recovery rate, $R$, which is the same for all names. The cumulated loss at $t$ is

$$
L(t)=\frac{(1-R)}{n} \sum_{i=1}^{n} 1_{\left\{\tau_{i} \leq t\right\}}
$$

At time $t$ the outstanding notional is

$$
N(t)=1-\frac{L(t)}{(1-R)}
$$

In a credit index, the protection leg pays, at default times, $\tau_{i}$, the loss, $d L\left(\tau_{i}\right)$, from start date Ta to maturity date Tm or until all names have defaulted. The discounted payoff of the protection leg is

$$
\phi_{t}^{T a, T m}=\int_{T a}^{T m} D(t, \mu) d L(\mu) \approx \sum_{J=A+1}^{M} D\left(t, T_{j}\right)\left[L\left(T_{j}\right)-L\left(T_{j-1}\right)\right]
$$

where $D\left(t, T_{j}\right)$ is a discount factor. The premium leg pays at times $T_{j} j=A+1, \ldots, M$ or until all names have defaulted a premium $K$ on the average $\hat{N}\left(T_{j}\right)$ of the outstanding notional $N(t)$ for $t \in\left(T_{j-1}, T_{J}\right]$. The discounted payoff of the premium leg is

$$
\psi_{t}^{T a, T m}(K)=\left\{\sum_{j=A+1}^{M} D\left(t, T_{j}\right) \int_{T_{j-1}}^{T}{ }_{j-1} N(t) d t\right\} K \approx\left\{\sum_{j=A+1}^{M} D\left(t, T_{j}\right) \alpha_{j}\left(1-\frac{L\left(T_{j}\right)}{(1-R)}\right)\right\} K
$$

where the discretization considers the outstanding notional at the end of the interval ( $T_{j-1}, T_{j}$, and the internal has length $\alpha_{j}$. The expectation under the risk neutral probability measure $Q$ makes it possible to value of the two legs

$$
\Pi\left(\phi_{t}^{T a, T m}\right)=E\left[\phi_{t}^{T a, T m} \mid F_{t}\right]
$$

which allows to define the index of the defaultable present value per basis point as

$$
\Pi\left(\gamma_{t}^{T a, T m}\right)=E\left[\gamma_{t}^{T a, T m} \mid F_{t}\right]
$$


or

$$
\Pi\left(\gamma_{t}^{T a, T m}\right)=E\left[\gamma_{t}^{T a, T m} \mid F_{t}\right]=E\left[\sum_{j=A+1}^{M} D\left(t T_{j}\right) \alpha_{j}\left(1-\frac{L\left(T_{j}\right)}{(1-R)}\right) \mid F_{t}\right]
$$

These equations open the way to determine the index spread

$$
S_{t}^{T a, T m}=\frac{\Pi\left(\phi_{t}^{T a, T m}\right)+\Pi\left(F_{t}^{T a}\right)}{\Pi\left(\gamma_{t}^{T a, T m}\right)}
$$

which makes it possible to define an option price for a portfolio of defaultable assets

$$
\Pi\left(\gamma_{t}^{T a, T m}\right) \operatorname{Black}\left(\widetilde{S}_{t}^{T a, T m}, K, \tilde{\sigma}_{t}^{T a, T m}, \sqrt{T_{a}}\right)
$$

This formula, however, has some problems because the spread $S_{t}^{T a, T m}$ is valid only when the denominator

$$
\Pi\left(\gamma_{t}^{T a, T m}\right)=\sum_{j=A+1}^{M} E\left[D\left(t, T_{j}\right) \alpha_{j}\left(1-\frac{L\left(T_{j}\right)}{1-R}\right) \mid F_{t}\right]
$$

is different from zero. This quantity could vanish if it is not different from zero in all states of the world. Specifically then, when

$$
\Pi\left(\gamma_{t}^{T a, T m}\right)=0
$$

the option price is undefined. It is therefore imperative to have

$$
\Pi\left(\gamma_{t}^{T a, T m}\right)>0
$$

Sub-filtration addresses this difficulty. Morini and Brigo define sub-filtration as

$$
\begin{aligned}
& F_{t}=Z_{t}^{i} \vee H_{t}^{i} \\
& Z_{t}^{i}=\sigma\left(\left\{\tau_{i}>\mu\right\}, \mu<t\right)
\end{aligned}
$$

where $Z_{t}^{i}$ is the filtration generated at the default time $\tau_{i}$ of the name $i$, with $i=1,2, \ldots, n$, while $H_{t}^{i}$ is a filtration representing the flow of all information except the default of the name i. 
To use this information, it is necessary to define a new stopping time

$$
\tilde{\tau}=\max \left(\tau_{1}, \tau_{2}, \ldots, \tau_{n}\right)
$$

and a new filtration $\hat{\mathrm{H}}_{t}$ such that

$$
\begin{aligned}
& F_{t}=\hat{Z}_{t} \vee \hat{H}_{t} \\
& \hat{Z}_{t}=\sigma(\{\hat{\tau}>\mu\}, u \leq t)
\end{aligned}
$$

where $\hat{\mathrm{H}}_{t}$ excludes from the flow of market information the information of a so-called "armageddon event" that corresponds to the default of all names in a portfolio.

Assuming that

$$
Q\left(\tau>t \mid H_{t}\right)>0 \text { a.s. }
$$

and using

$$
\gamma_{t}^{T a, T m}=1_{\{\hat{\tau}>T a\}} \gamma_{t}^{T a, T m}
$$

it is possible to define

$$
\hat{\Pi}\left(\gamma_{t}^{T a, T m}\right)=E\left[\gamma_{t}^{T a, T m} \mid \hat{\mathrm{H}}_{t}\right]
$$

which then opens the way to express

$$
\Pi\left(\gamma_{t}^{T a, T m}\right)=E\left[\gamma_{t}^{T a, T m} \mid F_{t}\right]=\frac{1_{\{\hat{\tau}>t\}}}{Q\left(\hat{\tau}>t \mid \hat{\mathrm{H}}_{t}\right)} E\left[\gamma_{t}^{T a, T m} \mid \mathrm{H}_{t}\right]
$$

or

$$
\Pi\left(\gamma_{t}^{T a, T m}\right)=\frac{1_{\{\hat{\tau}>t\}}}{Q\left(\hat{\tau}>t \hat{H}_{t}\right)} \hat{H}\left(\gamma_{t}^{T a, T m}\right)
$$

that ensures that

$$
\hat{\mathrm{H}}\left(\gamma_{t}^{T a, T m}\right)
$$

is never null. This then provides an effective definition of the index spread and the pricing of an index option. 


\section{References}

Andersen, L., J. Sidenius, and S. Basu, 2003, “All Your Hedges in One Basket,” Risk (November), pp. 67-72.

Avesani, R., K. Liu, A. Mirestean, and J. Salvati, 2006, "Review and Implementation of Credit Risk Models of the Financial Sector Assessment Program (FSAP),” IMF Working Paper, No. 06/134 (Washington: International Monetary Fund).

Avesani, R., A. Garcia-Pascau, and J. Li, 2006, “A New Risk Indicator and Stress Testing Tool: A Multi-factor Nth-to-Default CDS Basket,” IMF Working Paper, No. 06/105 (Washington: International Monetary Fund).

Bank for International Settlements, 2005, “An Explanatory Note on the Basel II IRB Risk Weight Functions,” Basel Committee on Banking Supervision.

Bates, D. S., 1996, “Jumps and Stochastic Volatility: Exchange Rate Processes Implicit in Deutsche Mark Options,” Review of Financial Studies, Vol. 9, pp. 69107.

Black, F., and M. S. Scholes, 1973, “The Pricing of Options and Corporate Liabilities,” Journal of Political Economy, Vol. 81, pp. 637-659.

Capuano, C., 2008, “The option-iPoD. The probability of default implied by option prices based on entropy.,” IMF Working Paper No. 08/194 (Washington: International Monetary Fund).

Ceci, C., and A. Gerardi., 2006, "A Model for High Frequency Data Under Partial Information: A Filtering Approach", International Journal of Theoretical and Applied Finance, Vol. 9, No. 4, pp. 555-576.

Çetin, U., R. Jarrow, P. Protter, and Y. Yildirim, 2004, “Modeling Credit Risks with Partial Information,” The Annals of Applied Probability, 14.

Chan-Lau, J. A., and T. Gravelle, 2005, “The END: A New Indicator of Financial and NonFinancial Corporate Sector Vulnerability,” IMF Working Paper No. 05/231 (Washington: International Monetary Fund).

Chan-Lau, J. A., A. Jobert, and J. Q. Kong, 2004, “An Option-Based Approach to Bank Vulnerabilities in Emerging Markets,” IMF Working Paper No. 04/33 (Washington: International Monetary Fund).

Chan-Lau, J. A., and A. O. Santos, 2006, “Currency Mismatches and Corporate Default Risk: Modeling, Measurement, and Surveillance Applications,” IMF Working Paper No. 06/269 (Washington: International Monetary Fund). 
Chan-Lau, J. A., and A. N. R. Sy, 2006, “Distance-to-Default: A Bridge Too Far?,” IMF Working Paper No. 06/215 (Washington: International Monetary Fund).

Couderc, F. 2007, “Measuring Risk on Credit Indices: On the Use of the Basis,” Riskmetrics Journal.

Crosbie, P., and J. R. Bohn, 2003, “Modeling Default Risk,” unpublished, Moody’s KMV Company.

Crouhy, M., D. Galai, and R. Mark, 2000, “A Comparative Analysis of Current Credit Risk Models,” The Journal of Banking and Finance, Vol. 24, pp. 59-117.

Duffie, D., and K. J. Singleton, 2003, Credit Risk: Pricing, Measurement, and Management (Princeton: Princeton University Press).

Duffie, D., and K. J. Singleton, 1999, “Modeling the Term Structures of Defaultable Bonds,” Review of Financial Studies 12 (4), pp. 687-720.

Duffie, D., and D. Lando, 2001, “Term Structure of Credit Spreads with Incomplete Accounting Information,” Econometrica, 69.

Duffie, D., A. Horel, and L. Saita, 2008, “Frailty Correlated Default,” unpublished.

Dumas, Bernard, L. Peter Jennergren, and Bertil Naslund, 1995, “Siegel’s Paradox and the Pricing of Currency Options,” Journal of International Money and Finance, Vol. 14, pp. 213-223.

Eisenberger, L., and T. Noe, 2001, “Systemic Risks in Financial Systems,” Management Science, Vol. 47, pp. 236-249.

Elizalbe, A., 2006, “Credit Risks Models III: Reconciliation Reduced-Structural Models,” CEMFI Working Paper No. 0607.

FitchRatings, 2004, "Demystifying Basel II: A Closer Look at the IRB Measures and Disclosure Framework,” August 25.

FitchRatings, 2008, “Basel II Correlation Values. An Empirical Analysis of EL, UL, and the IRB Model,” May 19.

Frey, R., and W. Runggaldier, 2007, “Credit Risk and Incomplete Information: A Nonlinear Filtering Approach,” unpublished, Universität Leipzig.

Frey, R., T. Schmidt, and A. Gabih, 2007, "Pricing and Hedging of Credit Derivatives Via Nonlinear Filtering,” unpublished, Universität Leipzig. 
Gapen, M., D. F. Gray, C. H. Lim, and Y. Xiao, 2004, “The Contingent Claims Approach to Corporate Vulnerability: Estimating Default Risk and Economy-Wide Risk Transfer,” IMF Working Paper No. 04/121 (Washington: International Monetary Fund).

Geske, R., 1977, “The Valuation of Corporate Liabilities as Compound Options,” Journal of Financial and Quantitative Analysis, Vol. 12, pp. 169-76.

Gibson, M. S., 2004, “Understanding the Risk of Synthetic CDOs,” Board of Governors of the Federal Reserve System, Washington.

Giesecke, K., 2005, “Default and Information,” Working Paper, Cornell University.

Giesecke, K., 2004, “Correlated Default with Incomplete Information,” Journal of Banking and Finance, 28.

Giesecke, K., and L. Goldberg, 2004, “Forecasting Defaults in the Face of Uncertainty,” Journal of Derivatives, 12.

Gropp, R., J. Vesala, and G. Vulpes, 2006, "Equity and Bond Markets Signals as Leading Indicators of Bank Fragility,” Journal of Money, Credit and Banking, Vol. 38, pp. 399-428.

Guo, X., R. A. Jarrow, and H. Lin, 2008, “Distressed Debt and Recovery Rate Estimation,” unpublished, University of California at Berkeley and Cornell University.

Guo, X., R. A. Jarrow, and Y. Zeng, 2005a, "Information Reduction in Credit Risks Models,” unpublished, Cornell University.

Guo, X., R. A. Jarrow, and Y. Zeng, 2005b, "Modeling the Recovery in a Reduced Form Model,” unpublished, Cornell University.

Harrison, J. M., and S. Pliska, 1981, "Martingales and Stochastic Integrals in the Theory of Continuous Trading,” Stochastic Processes and Their Applications, 11, pp. 215-260.

Harrison, J. M., and D. Kreps, 1979, "Martingales and Arbitrage in Multiperiod Security Markets,” Journal of Economic Theory, 20, pp. 381-408.

Huang, X., Zhou, H., Zhu, H., (2008), "A Framework for Assessing the Systemic Risk of Major Financial Institutions," Working Paper forthcoming, Board of Governors of the Federal Reserve.

International Monetary Fund, 2009, Global Financial Stability Report, April (Washington: International Monetary Fund). 
Jarrow, R. A., 2008, “Distressed Debt and Recovery Rate Estimation,” Presentation at Princeton University, May.

Jarrow, R. A., D. Lando, and S. Turnbull, 1997, “A Markov Model for the Term Structure of Credit Risk Spreads,” Review of Financial Studies 10 (2), pp.481-523.

Jarrow, R. A., and P. Protter, 2004, "Structural versus Reduced Form Models: A New Information Based Perspective,” Journal of Investment Management, 2.

Jarrow, R. A., and S. Turnbull, 1992, “Credit Risk: Drawing the Analogy,” Risk Magazine 5 (9).

Jarrow, R. A., and S. Turnbull, 1995, "Pricing Derivatives on Financial Securities Subject to Credit Risk,” Journal of Finance 50(1), pp. 53-85.

Jarrow, R. A., and F. Yu, 2001, “Counterparty Risk and the Pricing of Defaultable Securities,” The Journal of Finance, Vol. 56, pp. 1756-1799.

Jorion, P., 1988, “On Jump Processes in the Foreign Exchange and Stock Markets,” Review of Financial Studies, Vol. 1, pp. 427-455.

Joshi, M., and A. Stacey, 2005, “Intensity Gamma: A New Approach to Pricing Portfolio Credit Derivatives,” Working Paper, Royal Bank of Scotland, Quantitative Research Centre.

Karatzas, I., and S. Shreve, 1991, Brownian Motion and Stochastic Calculus, 2nd edition (New York: Springer).

Karr, A. F., 1993, Probability (New York: Springer-Verlag).

Kim, I., K. Ramaswamy, and S. Sundaresan, 1993, “The Valuation of Corporate Fixed Income Securities,” Financial Management, Vol. 22, 117-131.

Kou, Steven G., 2002, “A Jump-Diffusion Model for Option Pricing,” Management Science, Vol. 48, pp. 1086-1101.

Kuo, H.-H., 2006, Introduction to Stochastic Integration (New York: Springer).

Lando, D., 2004, Credit Risk Modeling: Theory and Application (Princeton: Princeton University Press).

Li, D. X., 2000, “On Default Correlation: A Copula Function Approach,” Journal of Fixed Income, March, pp. 115-118.

Longstaff, F., and E. S. Schwartz, 1995, “A Simple Approach for Valuing Risky Fixed and Floating Rate Debt,” The Journal of Finance, Vol. 50, pp. 789-819. 
McNeil, A. J., R. Frey, and P. Embrechts, 2005, Quantitative Risk ManagementConcepts, Techniques and Tools (Princeton: Princeton University Press).

Merton, R. C., 1974, “On the Pricing of Corporate Debt: the Risk Structure of Interest Rates,” The Journal of Finance, Vol. 29, pp. 449-470.

Morini, M., and D. Brigo, 2007, “Arbitrage-free pricing of Credit Index Options.

The no-armageddon pricing measure and the role of correlation after the subprime crisis,” unplublished, Banca IMI, Intesa-San Paolo, Department of Quantitative Methods, Bocconi University, Fitch Solutions, and Department of Mathematics, Imperial College.

Nielsen, L., J. Saá-Requejo, and P. Santa-Clara, 1993, “Default Risk and Interest Rate Risk: The Term Structure of Credit Spreads,” unpublished, University of California, Los Angeles.

Protter, Philip, 1992, Stochastic Integration and Differential Equations (New York: Springer Verlag).

Saá-Requejo, J., and P. Santa-Clara, 1999, “Bond Pricing with Default Risk,” unpublished, University of California, Los Angeles.

Schönbucher, P., 2008, “Time for a Time-Change: A New Approach to Multivariate Intensity Models of Credit risk,” Presentation at Princeton University, May.

Vacisek, O., 1987, “Probability of Loss on Loan Portfolios,” unpublished, Moody’s KMV.

Vassalou, M., and Y. Xing, 2004, “Default and Equity Returns,” The Journal of Finance, Vol. 59, pp. 831-868.

Wong, H. Y., and T. L. Wong, 2007, "Reduced-form Models with Regime Switching: An Empirical Analysis for Corporate Bonds,” Asia-Pacific Financial Markets 14, pp. 229-253. 